\title{
High Frequency of Advanced Hepatic Disease among HIV/HCV Co-Infected Patients in Cambodia: The HEPACAM Study (ANRS 12267)
}

Nathalie Lerolle ${ }^{1,5^{*}}$, Setha Limsreng ${ }^{2,3}$, Isabelle Fournier-Nicolle ${ }^{4,5}$, Sowath Ly ${ }^{5}$, Janin Nouhin ${ }^{6}$, Bertrand Guillard ${ }^{7}$, Sreymom Ken ${ }^{6}$, Anne Dulioust $^{1,2}$, Pichit Khuon ${ }^{2,3}$, Jean-François Delfraissy $y^{1,2,4}$, Vara Ouk $^{2,3}$ and Olivier Segeral ${ }^{1,2}$

${ }^{1}$ Assistance Publique - Hôpitaux de Paris (AP-HP), Département de Médecine Interne et Immunologie Clinique, Centre Hospitalier Universitaire de Bicêtre, 78 rue du Général Leclerc, 94276 Le Kremlin-Bicêtre, France

"Ensemble pour une Solidarité Thérapeutique Hospitalière En Réseau" (ESTHER), France

${ }^{3}$ Department of Internal Medicine Division of Infectious Diseases, Calmette Hospital, Phnom Penh, Cambodia

${ }^{4}$ Agence Nationale de Recherche sur le Sida et les hépatites virales (ANRS). France

${ }^{5}$ Epidemiology Unit, Institut Pasteur in Cambodia, Phnom Penh, Cambodia

${ }^{6}$ Laboratory of HIV/Hepatitis, Institut Pasteur in Cambodia, Phnom Penh, Cambodia

${ }^{7}$ Clinical Laboratory, Institut Pasteur in Cambodia, Phnom Penh, Cambodia

\section{Abstract}

Background: Little is known about HIV/Hepatitis C Virus (HCV) co-infection in resource-limited countries, although chronic HCV infection is one of the most relevant comorbidities in HIV population. The aim of this study was to determine the severity of liver disease in a cohort of HIV/HCV co-infected patients followed in Calmette Hospital, Phnom Penh, Cambodia, and to analyse the impact of HCV infection on antiretroviral therapy efficacy and hepatotoxicity.

Methods: HIV patients with positive HCV antibodies were enrolled in this cross-sectional study. HIV monoinfected patients formed the control group. Transverse evaluation of co-infected patients was performed collecting clinical, biological, virological and ultrasonographic data. HIV course, response to antiretroviral therapy and frequency of hepatocytolysis were compared in both groups.

Results: Among 50 HIV patients known with HCV antibodies, 31 (62\%) had positive plasma HCV RNA and were included ( $58 \%$ men, median age 44 years). HCV genotype 1 was the most prevalent $(68 \%)$, followed by genotype $6(25 \%)$. Twelve patients (39\%) met clinical, biological and/or ultrasonographic criteria for cirrhosis. FibroTest stage was 3-4 in 16 patients (52\%). HIV/HCV co-infected patients demonstrated similar immune restoration and virological response to antiretroviral therapy as the 160 HIV mono-infected patients. Co-infected patients were more likely to have alanine aminotransferase elevation at baseline and to develop grade 2 or 3 hepatocytolysis in the two years after antiretroviral therapy initiation, specifically when nevirapine was used during the first six months of treatment.

Conclusions: HIV/HCV co-infected patients are at increased risk for acquiring severe hepatic fibrosis. HCV coinfection does not affect response to ART. Efavirenz should be preferred to nevirapine in co-infected patients due to hepatotoxicity. Further research is required to target access to appropriate management of HIV/HCV co-infections in resource-limited countries.

Keywords: HIV; HCV co-infection; Fibrotest; Cirrhosis; Resourcelimited country; Nevirapine

Abbreviations: HIV: Human Immunodeficiency Virus; HCV: Hepatitis C Virus; ART: Antiretroviral Therapy; ALT: Alanine Aminotransferase; HAART: Highly Active Antiretroviral Therapy; ART: Antiretroviral Therapy; AIDS: Acquired Immune Deficiency Syndrome; PLWHA: People Living with HIV/AIDS; ARV: Antiretroviral; EFV: Efavirenz; NVP: Nevirapine; HBV: Hepatitis B Virus; HbsAg: HBs Antigen; OR: Odds Ratios; SVR: Sustained Virological Response

\section{Introduction}

Since the advent of highly active antiretroviral therapy (HAART), both mortality and incidence of new-Acquired Immune Deficiency Syndrome (AIDS) defining events have dramatically declined among people living with HIV/AIDS (PLWHA) in developed countries [1,2]. Accordingly, the main underlying causes of morbidity and mortality in this population are more frequently associated to non HIV-related conditions such as neoplasia, cardiovascular diseases and chronic viral hepatitis $[3,4]$. In France, hepatitis $\mathrm{C}$ virus (HCV) was found to be the third cause of death among PLWHA between 2000 and 2005 [5], and in the Data collection on Adverse events of anti-HIV Drugs (D:A:D study), liver disease was the first cause of non-AIDS related death [4]. Compared to HIV sero-negative patients, HCV course among PLWHA is more severe: progression to cirrhosis occurs faster [6], and global survival is shortened [7]. Moreover, liver toxicity of ART is a source of growing concern and seems to be magnified by HCV co-infection [810]. Data are more controversial regarding the potential impact of $\mathrm{HCV}$ co-infection on HIV disease progression and immune reconstitution with ART [11].

In developing countries, stimulated by the " 3 by 5 " and Universal Access initiatives from the World Health Organization (WHO) and UNAIDS (United Nations Programme on HIV/AIDS), a growing number of PLWHA gained access to ART: by the end of 2008, 4 million

*Corresponding author: Nathalie Lerolle, Assistance Publique - Hôpitaux de Paris (AP-HP), Département de Médecine Interne et Immunologie Clinique, Centre Hospitalier Universitaire de Bicêtre, 78 rue du Général Leclerc, 94276 Le Kremlin-Bicêtre France, Tel: 33145212891; Fax: 33145212741; E-mail: nathalie.lerolle@gmail.com

Received June 15, 2012; Accepted July 05, 2012; Published July 08, 2012

Citation: Lerolle N, Limsreng S, Fournier-Nicolle I, Ly S, Nouhin J, et al. (2012) High Frequency of Advanced Hepatic Disease among HIV/HCV Co-Infected Patients in Cambodia: The HEPACAM Study (ANRS 12267). J AIDS Clinic Res 3:161. doi:10.4172/2155-6113.1000161

Copyright: @ 2012 Lerolle N, et al. This is an open-access article distributed unde the terms of the Creative Commons Attribution License, which permits unrestricted use, distribution, and reproduction in any medium, provided the original author and source are credited. 
had started the treatment. In 13.4 million inhabitants Cambodia, the number of PLWHA on first-line antiretroviral (ARV) regimen has significantly increased in the last 6 years, reaching more than 40,000 at the end of 2010 , which covers $80 \%$ of those who needed the treatment based on the WHO 2010 recommendations (Cambodian Ministry of Health's annual report). ART access programs have proven the feasibility and efficacy of first-line ARV regimen in resource-limited settings similarly to those reported in developed countries $[12,13]$. In Cambodia, similar positive outcomes was reported after two and three years of first-line ARV regimen combining retrovir (AZT) or stavudine (d4T), epivir (3TC), and nevirapine (NVP) or efavirenz (EFV) [14-18]. As AIDS-related morbidity and mortality are declining in Cambodia, the burden of HIV/chronic viral hepatitis co-infection will likely increase in the near future. However, little is known about viral hepatitis in Cambodia. The prevalence in the overall Cambodian population ranges from 8 to $9 \%$ for hepatitis B and 6 to $14 \%$ for hepatitis C according to Cambodian unpublished and published surveys [19-21]. Compared with neighbouring countries, the prevalence of hepatitis B is similar but the prevalence of hepatitis C appears to be greater [22,23]. The high frequency of therapeutic injections practices before the 1990s in Cambodia could explain this difference [24], whereas intravenous drug abuse seems marginal. The prevalence of HIV/HCV co-infection is not precisely known in the different Cambodian HIV care centres, as HCV antibodies are not routinely screened in the country, but it was estimated to be around $10 \%$ in ESTHER/Calmette cohort, Phnom Penh, Cambodia, in a recent survey. Accurate assessment of the extent of liver disease among HIV/HCV co-infected patients in Cambodia, as in most developing countries, is lacking.

The study aimed at evaluating the ratio of active hepatitis among positive HCV antibodies patients and to describe the severity of hepatic disease, specifically the stage of fibrosis, among HIV/HCV co-infected patients. Secondary objectives were to identify major HCV genotypes circulating in this population and to analyse response to ART and hepatic toxicity of drugs among HIV/HCV co-infected patients compared to a HIV mono-infected control group.

\section{Patients and Methods}

\section{Study population}

A cross sectional study was conducted from March to June 2009 among patients issued from the "Ensemble pour une Solidarité Thérapeutique Hospitalière En Réseau" (ESTHER) cohort followed at Calmette Hospital in Phnom Penh, Cambodia. The French ESTHER program was implemented in this hospital in February 2003 in collaboration with the Cambodian Ministry of Health. ART initiation began in July 2003 according to WHO recommendations and National Guidelines. The initial first-line regimen was d4T/3TC/EFV. To avoid $\mathrm{d} 4 \mathrm{~T}$ toxicity and because of EFV supply difficulties, the AZT/3TC/ NVP combination was progressively introduced and has become the initial combination since July 2004. Patients are clinically followed every month. CD4 counts are evaluated every 6 months but viral load monitoring is not routinely available. Nurses provide adherence support via a patient education program. In 2006, viral load assessment of the ESTHER Cohort was $<250$ copies in $69 \%$ of all patients and in $83 \%$ of naive patients in intent to treat analysis at 36 months [18]. At the time of the study, around 1400 PLWHA were followed-up in ESTHER/ Calmette cohort and 1200 were treated with ART. In 2007, 507 patients, among the 1000 patients followed at this time, have been screened for
HCV and Hepatitis B Virus (HBV) antibodies thanks to a financial support of ESTHER program (enzyme immunoassay, EIA 3.0, Abbott Laboratories). Screening was made gradually among patients seen in consultation and without selection criteria. HCV antibodies were positive for 52 patients (10.5\%) and HBs Antigen (HbsAg) for 63 (12\%) patients (personal unpublished data).

For inclusion in our study, HCV status was retrieved from the ESTHER/Calmette cohort database. Qualitative measurement of plasma HCV RNA was performed in all patients with positive HCV antibodies. Patients were eligible if they had positive HCV antibodies and detectable plasma HCV RNA. Patients were not eligible if plasma HCV RNA was negative, if they were pre-treated or treated with antiHCV therapy, or if they were enrolled in a prospective study. The selected Control group consisted of HIV infected patients (ratio 3/1) with negative HCV antibodies followed at the Hospital's outpatient clinic during the study period and randomly chosen. HCV antibodies were controlled after inclusion among all control patients (enzyme immunoassay, EIA 3.0, Abbott Laboratories). HBV status was not restricted but was adjusted in analysis.

\section{Assessment of liver disease among HIV-HCV co-infected patients}

Transverse evaluation of $\mathrm{HIV} / \mathrm{HCV}$ co-infected patients was performed by collecting clinical, biological, virological and ultrasonographic data during follow-up visits, from March to June 2009. Information about socio-demographic background, lifestyle (including alcohol intake [25], tobacco and illicit drug use), previous hepatic history and detailed physical examination (including vital signs, body mass index, hepatomegaly, splenomegaly, jaundice, ascites, collateral venous circulation, spider angiomata, leukonychia, palmar erythema, encephalopathy) were collected on a standardised case report form. In addition to the routine blood tests and HBV/HCV serology, prothrombin time, serum albumin level, alpha-fetoprotein (Calmette Hospital), and FibroTest-ActiTest (Clinical Laboratory, Institut Pasteur in Cambodia) were obtained. The results from FibroTest-ActiTest were analysed on automated system Integra 400 (Roche Diagnostics) following manufacturer's protocol (Bio predictive, Paris, France). An abdominal ultrasound was performed, within two days following inclusion, to look for hepatomegaly, steatosis, and signs of liver cirrhosis, ascites, portal hypertension and focal hepatic lesions.

\section{Virological analysis}

Qualitative measurement of HCV RNA and HCV genotyping was performed in the HIV/Hepatitis Laboratory, Pasteur Institute in Cambodia, as described below. HCV RNA was extracted from 140 $\mu \mathrm{L}$ of plasma using QIAamp Viral RNA mini kit (Qiagen, Hilden, Germany). Extracted RNA was immediately used for qualitative RNA viral load and viral genotyping. Qualitative HCV RNA viral load was assed using reverse transcription (RT) and nested-PCR amplification of 5'NC region. The cut-off value of detection was 100 copies per ml.

HCV Genotyping was performed by Reverse transcription and nested-PCR amplification of NS5B region as previously described $[26,27]$. The nested-PCR amplified fragments were sent to the Macrogen Company (Macrogen Inc., Seoul, Republic of Korea). Chromatograms sent back electronically to the Pasteur Institute were interpreted using Ceq2000 (Beckman Coulter) software. Virus subtypes were determined by sequence analysis of amplified fragments using CLUSTAL X 1.81 software and the subtype sequences reference sets from the Genbank database. 


\section{Comparison with HIV mono-infected control group}

In order to compare $\mathrm{HIV} / \mathrm{HCV}$ co-infected patients with HIV mono-infected patients, socio-demographic background and lifestyle data were collected. HIV disease progression, clinical, immunological (Cyflow, Partec, Germany) and virological (real-time PCR, ANRS, France) response to ART and hepatotoxicity (e.g. ALT at screening and 6, 12 and 24 months after ART initiation) were retrospectively analysed using the outpatient database, and compared between HIV/HCV coinfected and HIV mono-infected patients. Normal values of ALT were defined as 19U/L for women and 31U/L for men. Hepatocytolysis grade 2 was defined as ALT $>2.5 \mathrm{x}$ normal values and grade 3 as ALT $>5$ times normal values.

\section{Ethical aspects}

The study received approval from the Cambodian National Ethics Committee for Health Research (NECHR). A signed informed consent form was required from each patient before inclusion in the study. Data collection was anonymous and stored safely in a computer.

\section{Statistical analysis}

Comparison between HIV/HCV co-infected and HIV monoinfected patients was made using Chi-square test or Fischer test for qualitative variables, and Student test or Kruskal-Wallis test for quantitative variables. Crude association between cases and controls was determined by estimating the Odds ratios (OR) and their $95 \%$ CI. This was done by bivariate logistic regression, adjusted for age (in $\mathrm{x}$-year classes), residence and HBV status. OR significance was assessed by the likelihood test. Adjusted ORs were reported. Statistical analysis was performed using STATA 2010 (Texas, USA).

\section{Results}

\section{Virological results}

Between March and June 2009, 52 HIV infected patients with $\mathrm{HCV}$ positive antibodies were enrolled in the study. Two patients were excluded: one because of ongoing treatment for hepatitis $\mathrm{C}$ and one because of previous inclusion in a prospective trial study. Qualitative PCR for HCV was positive for 31 patients (62\%). HCV genotyping could be done for 28 patients: genotype 1 was the most common (68\%), followed by genotype $6(25 \%)$ and genotype $2(7 \%)$. Amplification failed for three patients.

\section{Characteristics of hepatic disease among HIV/HCV co- infected patients}

HCV infection was diagnosed around a median of 29 months. No diagnosis of cirrhosis was made before enrolment in our study. Based on physical examination, two patients had clinical signs suggestive of cirrhosis (jaundice without other explanation for one patient and collateral venous circulation for the other). Serum liver function tests were consistent with cirrhosis in eight patients (prothrombin time $\leq$ 70\%: five patients; bilirubinemia $>35 \mathrm{mg} / \mathrm{l}$ : three patients), whereas albuminemia and $\alpha$-fetoprotein were normal in all patients. Abdominal ultrasound revealed signs of chronic hepatopathy in five patients (dysmorphic liver: two patients; widened portal vein diameter: three patients; splenomegaly: three patients). No patients had ascites, portal thrombosis or suspicious focal liver lesion. Twelve patients (39\%) presented at least one criterion for possible cirrhosis (Table 1).

Non-invasive assessment of hepatitis activity and liver fibrosis (FibroTest-ActiTest) is shown in Table 1. The severity of liver inflammation was graded 2-3 in 12 patients (39\%). Advanced hepatic fibrosis (i.e. FibroTest stage 3-4) was found in 16 patients (52\%) and significantly correlated with the presence of, at least, one criterion for cirrhosis $(\mathrm{p}=0.043)$. FibroTest revealed stage $0-1$ for ten patients $(32 \%)$ and stage 2 for five patients (16\%). Overall, $68 \%$ of patients presented a fibrosis score $\geq 2$.

\section{Comparison of $\mathrm{HIV} / \mathrm{HCV}$ co-infected patients with HIV mono-infected control subjects}

Demographic, behavioural and general medical data are reported in Table 2. Median age was 44 years, and $58 \%$ of the population was male. More than half of the patients came from Phnom Penh or its suburb of Kandal. The majority of patients were married or widowed and had children. Seven patients (23\%) were heavy alcohol users and all patients denied any intravenous drug use history. HBsAg was detected in one patient, whereas half of the study population had cured hepatitis B (data not showed).

HIV/HCV co-infected and HIV mono-infected patients were compared according to general characteristics (Table 2), duration of HIV infection, clinical, immunological and virological response to ART

\begin{tabular}{|l|c|}
\hline Median HCV duration in months (IQR) & $29(25-51)$ \\
\hline Criteria of cirrhosis & \\
$\quad \geq 1$ clinical criterion*, N (\%) & $2(7)$ \\
$\geq 1$ biological criterion*,$N(\%)$ & $8(26)$ \\
$\geq 1$ echographic criterion ${ }^{* * *}, \mathrm{~N}(\%)$ & $5(16)$ \\
$\geq 1$ criterion among clinical, biological and echographic, N (\%) & $12(39)$ \\
2 types of criterion, N (\%) & $3(10)$ \\
3 types of criterion, N (\%) & 0 \\
\hline ActiTest-FibroTest results & $19(61)$ \\
A: O/1, N (\%) & $12(39)$ \\
$2 / 3, N(\%)$ & $10(32)$ \\
F: $0 / 1, N(\%)$ & $5(16)$ \\
$2, N(\%)$ & $16(52)$ \\
$3 / 4, N(\%)$ & \\
\hline
\end{tabular}

IQR: Interquartile Ratio

*Ascites, collateral venous circulation, splenomegaly, jaundice and/or encephalopathy without other explanation

${ }^{* *}$ Prothrombin time $\leq 70 \%$ and/or bilirubinemia $>35 \mathrm{mg} / \mathrm{l}$ without other explanation ${ }^{* * *}$ Dysmorphic liver, increased diameter of portal vein, ascites, portal thrombosis and/or suspect liver focal lesion without other explanation

Table 1: Characteristics of hepatic disease among PLWHA with active hepatitis $\mathrm{C}(\mathrm{N}=31)$.

\begin{tabular}{|l|l|l|l|}
\hline & $\begin{array}{l}\text { HIV/HCV co- } \\
\text { infected patients } \\
(\mathrm{N}=31)\end{array}$ & $\begin{array}{l}\text { HIV mono- } \\
\text { infected patients } \\
(\mathrm{N}=160)\end{array}$ & p value \\
\hline $\begin{array}{c}\text { Median age in years (IQR) } \\
<30, \mathrm{~N}(\%)\end{array}$ & $\begin{array}{l}44(38-51) \\
3(10)\end{array}$ & $\begin{array}{l}39(35-45) \\
17(11)\end{array}$ & 0.038 \\
$\begin{array}{c}31-40, \mathrm{~N}(\%) \\
41-50, \mathrm{~N}(\%)\end{array}$ & $\begin{array}{l}9(29) \\
11(35)\end{array}$ & $\begin{array}{l}48(30) \\
13(8)\end{array}$ & \\
\hline Gender, male, N (\%) & $8(26)$ & $85(53)$ & 0.61 \\
\hline Residence, Phnom Penh, N (\%) & $18(58)$ & $122(76)$ & 0.005 \\
\hline Marital status, married, N (\%) & $16(52)$ & $113(71)$ & 0.61 \\
\hline Duration of HIV infection in years (IQR) & $7(4-9,5)$ & $6(5,5-7)$ & 0.79 \\
\hline Heterosexual HIV transmission, N (\%) & $31(100)$ & $160(100)$ & \\
\hline Injected drug use, N (\%) & $0(0)$ & $0(0)$ & 0.047 \\
\hline HBsAg positive, N (\%) & $1(3)$ & $25(16)$ & 0.68 \\
\hline Alcohol daily consumption, N (\%) & $7(23)$ & $31(19)$ & \\
\hline
\end{tabular}

IQR: Interquartile Ratio

Table 2: General data among HIV/HCV co-infected patients and comparison to HIV mono-infected patients. 
Citation: Lerolle N, Limsreng S, Fournier-Nicolle I, Ly S, Nouhin J, et al. (2012) High Frequency of Advanced Hepatic Disease among HIV/HCV CoInfected Patients in Cambodia: The HEPACAM Study (ANRS 12267). J AIDS Clinic Res 3:161. doi:10.4172/2155-6113.1000161

Page 4 of 7

(Table 3), and frequency of hepatocytolysis before and after initiation of ART (Table 4).

Comparison of demographic data revealed no statistically significant differences in terms of gender, marital and familial status, but co-infected subjects were older (median age 44 versus 39 years, $\mathrm{p}=$ 0.038), and were more likely to reside outside of Phnom Penh or Kandal provinces ( $48 \%$ vs. $24 \%$, $\mathrm{p}=0.005$ ). Remarkably, HBV co-infection was more frequent in control subjects ( $16 \%$ vs. $3 \%, \mathrm{p}=0.047)$.

Duration of HIV infection (i.e. time since diagnosis), frequency of ART pre-treatment before inclusion in the cohort, incidence of AIDS, baseline CD4 cell count, ART proportion and ART duration were similar in both groups. Clinical, immunological and virological therapeutic responses were also equivalent. At baseline and at the time of the study, ART regimens were comparable in the two populations (nevirapine, efavirenz, or protease inhibitors-based regimens).

Co-infected patients were more likely to have grade 2 ALT elevation at baseline $(30 \%$ vs. $14 \%, \mathrm{p}=0,017)$ and to develop grade 2 or more hepatocytolysis six months after ART initiation in case of nevirapine use ( $46 \%$ vs. $11 \%, p=0.08$ ). In all cases, the likelihood to experience at least one episode of hepatic cytolysis grade 2 or 3 during the first two years of treatment was significantly higher in HIV/HCV co-infected patients ( $42 \%$ vs. $13 \%, \mathrm{p}=0.004$ for grade 2 and $29 \%$ vs. $8 \%, \mathrm{p}=0.007$ for grade 3$)$.

\section{Discussion}

Among the $50 \mathrm{HIV}$ infected patients with $\mathrm{HCV}$ positive antibodies, $62 \%$ had active HCV defined by positive plasma HCV PCR. This result

\begin{tabular}{|c|c|c|c|c|}
\hline & HIV/HCV co-infected patients $(\mathrm{N}=31)$ & HIV mono-infected patients $(\mathrm{N}=160)$ & Crude OR & $p$ value \\
\hline $\begin{array}{l}\text { Duration of HIV infection in months } \\
\quad<60, \mathrm{~N}(\%) \\
60-90, \mathrm{~N}(\%) \\
>90, \mathrm{~N}(\%)\end{array}$ & $\begin{array}{l}13(46) \\
8(29) \\
7(25)\end{array}$ & $\begin{array}{l}78(53) \\
52(35) \\
18(12)\end{array}$ & $\begin{array}{l}1 \\
0.85(0.31-2.31) \\
2.39(0,75-7.62)\end{array}$ & $\begin{array}{l}0.75 \\
0.14\end{array}$ \\
\hline ART Pre-treated, N (\%) & $16(53)$ & $53(34)$ & $1.94(0.82-4.62)$ & 0.13 \\
\hline CDC stage $\mathrm{C}, \mathrm{N}(\%)$ & $12(40)$ & $49(32)$ & $1.41(0.63-3.18)$ & 0.39 \\
\hline $\begin{array}{l}\text { Median baseline CD4 cell count, cells } / \mathrm{mm}^{3} \text { (IQR) } \\
<50, \mathrm{~N}(\%) \\
50-200, \mathrm{~N}(\%) \\
>200, \mathrm{~N}(\%)\end{array}$ & $\begin{array}{l}171(32-295) \\
10(32) \\
9(29) \\
12(39)\end{array}$ & $\begin{array}{l}113(44-258) \\
46(29) \\
64(40) \\
50(31)\end{array}$ & $\begin{array}{l}1 \\
0.63(0.22-1.79) \\
1.17(0.44-3.13)\end{array}$ & $\begin{array}{l}0.58 \\
0.39 \\
0.75\end{array}$ \\
\hline $\begin{array}{l}\text { ART treated at the time of the study }(\%) \\
\text { NVP-based regimen } \\
\text { EFV-based regimen } \\
\text { PI-based regimen }\end{array}$ & $\begin{array}{l}28(90) \\
15(54) \\
7(25) \\
6(21)\end{array}$ & $\begin{array}{l}150(94) \\
94(64) \\
26(18) \\
25(17)\end{array}$ & $\begin{array}{l}0.40(0.09-1.68) \\
0.65(0.27-1.56) \\
1.61(0.58-4.47) \\
1.28(0.43-3.84)\end{array}$ & $\begin{array}{l}0.21 \\
0.33 \\
0.36 \\
0.66\end{array}$ \\
\hline $\begin{array}{l}\text { ART duration in months } \\
\quad<36, \mathrm{~N}(\%) \\
\quad 36-60, \mathrm{~N}(\%) \\
>60, \mathrm{~N}(\%)\end{array}$ & $\begin{array}{l}9(32) \\
9(32) \\
10(36)\end{array}$ & $\begin{array}{l}32(21) \\
37(25) \\
81(54)\end{array}$ & $\begin{array}{l}1 \\
0.75(0.24-2.31) \\
0.34(0.11-1.01)\end{array}$ & $\begin{array}{l}0.62 \\
0.053\end{array}$ \\
\hline Opportunistic infection upon ART, N (\%) & $6(29)$ & $24(20)$ & $1.88(0.61-5.81)$ & 0.27 \\
\hline $\begin{array}{l}\text { Median latest CD4 cell count, cells } / \mathrm{mm}^{3} \text { (IQR) } \\
\quad<200, \mathrm{~N}(\%) \\
\quad 200-350, \mathrm{~N}(\%) \\
\quad>350, \mathrm{~N}(\%)\end{array}$ & $\begin{array}{l}372(283-472) \\
7(22) \\
8(26) \\
16(52)\end{array}$ & $\begin{array}{l}324(227-422) \\
26(16) \\
67(42) \\
67(42)\end{array}$ & $\begin{array}{l}1 \\
0.61(0.18-2.03) \\
1.16(0.38-3.58)\end{array}$ & $\begin{array}{l}0.94 \\
0.42 \\
0.79\end{array}$ \\
\hline $\begin{array}{l}\text { Median CD4 cell count gain under ART, cells / } \\
\mathrm{mm}^{3}(\mathrm{IQR})\end{array}$ & $160(0-280)$ & $183(78-280)$ & & 0.51 \\
\hline Latest $\log _{10}$ HIV RNA>250 copies/ml, N (\%) & $3(11)$ & $17(12)$ & $0.86(0.20-3.53)$ & 0.83 \\
\hline WHO immunological failure*, N (\%) & $9(29)$ & $28(17,5)$ & $1.85(0.73-4.70)$ & 0.20 \\
\hline WHO clinical and/or immunological failure ${ }^{*}, \mathrm{~N}(\%)$ & $14(52)$ & $49(37)$ & $2.00(0.83-4.83)$ & 0.12 \\
\hline
\end{tabular}

IQR: Interquartile ratio; CDC: Center for Disease Control and Prevention; ART: Antiretroviral Therapy; EFV: Efavirenz; NVP: Nevirapine; PI: Protease Inhibitors; WHO: World Health Organization

*WHO definition of treatment failure: immunological failure = CD4 decrease to pre-therapy baseline or below, $50 \%$ fall from the on-treatment peak value, or persistent CD4 levels $<100 \mathrm{cell} / \mathrm{mm}^{3}$; clinical failure $=$ new or recurrent WHO stage 4 or certain stage 3 conditions

Table 3: Comparison of HIV/HCV co-infected and HIV mono-infected patients adjusted for age, residence and HBV status, HIV course and ART response.

\begin{tabular}{|c|c|c|c|c|}
\hline & HIV/HCV co-infected patients $(\mathrm{N}=31)$ & HIV mono-infected patients $(\mathrm{N}=160)$ & Crude OR & $\mathrm{p}$ value \\
\hline Cytolysis grade $2^{*}$ at baseline, $\mathrm{N}(\%)$ & $9(30)$ & $22(14)$ & $3.46(1.25-9.60)$ & 0.017 \\
\hline $\begin{array}{l}\text { Cytolysis grade 2, } 6 \text { months after ART initiation, N (\%) } \\
\text { NVP-based regimen } \\
\text { EFV- based regimen }\end{array}$ & $\begin{array}{c}6(23) \\
6(46), N=13 \\
0, N=13\end{array}$ & $\begin{array}{c}14(9) \\
6(11), N=56 \\
8(9), N=86\end{array}$ & $\begin{array}{c}2.94(0.93-9.33) \\
4.19(0.84-20.80)\end{array}$ & $\begin{array}{c}0.067 \\
0.08 \\
0.31\end{array}$ \\
\hline$\geq 1$ cytolysis grade 2 during the first two years of ART, N (\%) & $10(42), N=24$ & $18(13), \mathrm{N}=138$ & $4.71(1.66-13.36)$ & 0.004 \\
\hline$\geq 1$ cytolysis grade $3^{* *}$ during the first two years of ART, N (\%) & $7(29), N=24$ & $10(8), N=134$ & $5.52(1.59-19.16)$ & 0.007 \\
\hline
\end{tabular}

${ }^{*} \mathrm{ALT}$ value $>2.5 \mathrm{x}$ normal value

${ }^{* *}$ ALT value $>5 x$ normal value

Table 4: Comparison of HIV/HCV co-infected and HIV mono-infected patients adjusted for age, residence and HBV status, cytolysis at baseline and on ART. 
is lower than those reported in developed countries, which vary from 70 to $80 \%$. Presence of false positive antibodies with EIA (Ortho HCV 3.0) [28] could explain this difference. Genotyping revealed genotype 1 predominance, followed by genotype 6 . This pattern is similar to the distribution amongst Vietnamese blood donors [29] but differs from Thailand, where genotype 3 is predominant [30]. The latter discrepancy could be explained by the absence of intravenous drug users in our cohort.

Half of the 31 patients with active HCV infection had advanced hepatic fibrosis according to FibroTest results, most of them meeting at least one criterion of cirrhosis, although none were previously diagnosed with such disease. This finding is consistent with those reported in the French ANRS HC02 (Ribavic) study, where liver biopsies suggested bridging fibrosis or cirrhosis in $40 \%$ of patients [31]. Ideally, hepatic fibrosis should be evaluated by liver biopsy. However, the associated costs, risks and need for a trained examining pathologist render the procedure impractical in a resource-limited context. The FibroTest measurement of HCV biomarkers has been proven to have a prognostic value similar to that of liver biopsy, especially for severe fibrosis, even if several conditions, such as infection, inflammation or hemolysis, can invalidate its results [32-34]. Moreover, HIV infection does not seem to affect the performance of non-invasive markers of fibrosis [35], and in our study, the finding of severe fibrosis was significantly associated with the presence of at least one criterion for cirrhosis. Thus, implementing liver fibrosis blood tests and elastometry should be a valuable diagnostic contribution $[32,34]$ in resource-limited settings may be essential.

This study is the first assessing virological data and liver disease evaluation among HIV/HCV co-infected patients in Cambodia. Some limitations deserve to be cited: patients seen in Calmette Hospital, a tertiary care center in the main town of Cambodia, may not be representative of those in the general community. Moreover, our small population size consisted only of patients whose HCV status was available, actually half of the entire cohort. Therefore, the estimated prevalence of HIV/HCV co-infection in our cohort is still unclear, as in the Cambodian population, and seroprevalence assays must be promoted further in the future. Although the seroprevalence survey performed in our cohort in 2007 was supposed to screen half of the patients without particular criteria, some additional patients may have been tested for HBV and HCV status because of liver dysfunction, which could have biased the study population.

Comparison between HIV/HCV co-infected patients and HIV mono-infected patients demographics in our study population indicated that co-infected patients were older and more likely to live outside Phnom Penh. The high frequency of unsafe therapeutic injections in Cambodia before the year 2000 [24] was suspected to be the cause of HCV epidemic infection, and could explain the disparities in age and geographic origin in this study. For that reason, potential confounding effects of those incomparable variables were adjusted in analysis. Further studies are needed to estimate the past and actual routes of HCV transmission in general population and PLWHA in Cambodia.

Amongst ART treated patients, HIV disease progression and clinical, immunological and virological responses were not different between the two populations. These results contradict findings from developed countries. Several studies suggest that active HCV infection affects immune restoration, even after years of exposure to ART [36,37]. Others studies indicate that mortality and increase in CD4 T-cell count do not differ during ART administration [38]. Confounding factors such as drug or alcohol use might be associated with poorer outcomes in co-infected patients in developed countries, but in this study no patients declared being intravenous drug users, and daily alcohol consumption was similar in HIV/HCV co-infected patients compared with HIV mono-infected patients.

After ART initiation, hepatocytolysis grade 2 and 3 occurred more frequently in HIV/HCV co-infected patients. However, the difference between the two groups was statistically significant mainly for nevirapine-containing regimens. Similarly, several studies in developed countries have revealed that chronic $\mathrm{HCV}$ infection is associated with an increased risk of drug-induced hepatotoxicity, especially with the use of nevirapine [9,39-41]. Nevirapine should probably be avoided in co-infected patients, and efavirenz should be the drug of choice whenever possible. However, a recent study in Cameroon suggests that this adverse event did not impact negatively on the effectiveness of treatment [42]. Moreover, ART slows down the progression of hepatic fibrosis and improves survival in co-infected patients [43], and hepatotoxicity of ART is reduced after successful treatment of HCV [44]. For these reasons, the control of HIV disease must be the ultimate priority in the management of co-infected patients.

Among the 31 co-infected patients, 21 (68\%) presented indications for HVC treatment according to current French recommendations (Fibrosis score $\geq 2$ ). None of these subjects demonstrated criteria for decompensated cirrhosis, suggesting that all patients with severe fibrosis were potentially treatable. HCV treatment in resource-limited settings is profoundly limited due to the prohibitive cost of the drugs and diagnostic tools, the need for cold-chain and the difficulties to manage the side effects. However, in the absence of treatment, these patients rapidly develop cirrhosis-related complications and are at increased risk of mortality from HCV infection. In Southeast Asia, increasing evidences support that $\mathrm{HCV}$ infected patients are more likely to achieve sustained virological response (SVR) than Caucasians with corresponding treatment regimen [45], probably because of the high proportion of genotype $6[29,30]$ and of particular genetic polymorphisms of IL28B in East Asian population, which are both associated with high therapeutic success rate $[46,47]$.

In conclusion, this study demonstrates the urgent need to develop HCV screening, as well as to increase access to virological assay and fibrosis assessment for $\mathrm{HCV}$-infected individuals in developing countries, specifically among PLWHA, since liver disease progresses faster in these patients. Early therapeutic intervention should be implemented in affected individuals to prevent progression into decompensated cirrhosis and death. We expect that our preliminary data will lead to further investigations, in order to determine the feasibility and effectiveness of treatments of chronic HCV among PLWHA, in Cambodia and other resource-limited countries, and will help to improve health policies about management of HIV/HCV coinfection in these settings.

\section{Authors Contributions}

NL contributed to the study design, participant enrolment and follow-up and manuscript preparation. SL contributed to study design. IFN contributed to study design and data analysis. SL contributed to data analysis. JN and SK contributed to virological analysis. BG contributed to study design and FibroTest performance. $A D, P K, J F D$ and VO contributed to study design. OS contributed to the study design, data analysis and manuscript preparation. All authors read and approved the final manuscript.

\section{International Conflicts of Interest}

JFD declared being board membership for BM, MSD and Gilead. 
Citation: Lerolle N, Limsreng S, Fournier-Nicolle I, Ly S, Nouhin J, et al. (2012) High Frequency of Advanced Hepatic Disease among HIV/HCV CoInfected Patients in Cambodia: The HEPACAM Study (ANRS 12267). J AIDS Clinic Res 3:161. doi:10.4172/2155-6113.1000161

\section{Acknowledgements}

The authors wish to thank all the patients who accepted to participate in this study; the doctors, nurses and technicians of Calmette Hospital and Institut Pasteur in Cambodia; ANRS, Alternat' HIV and Institut Pasteur in Cambodia for supporting this study; Pr. Thierry Poynard from BioPredictive, who generously offered us to use the FibroTest online calculation system for free; Jean-Charles Duclos-Vallée and Oscar Lahoud for reviewing the manuscript; and ESTHER program for their continued support and funding.

\section{References}

1. Palella FJ Jr, Delaney KM, Moorman AC, Loveless MO, Fuhrer J, et al. (1998) Declining morbidity and mortality among patients with advanced human immunodeficiency virus infection. HIV Outpatient Study Investigators. N Engl J Med 338: 853-860.

2. Egger M, May M, Chene G, Phillips AN, Ledergerber B, et al. (2002) Prognosis of HIV-1-infected patients starting highly active antiretroviral therapy: a collaborative analysis of prospective studies. Lancet 360: 119-129.

3. Mocroft A, Brettle R, Kirk O, Blaxhult A, Parkin JM, et al. (2002) Changes in the cause of death among HIV positive subjects across Europe: results from the EuroSIDA study. AIDS 16: 1663-1671.

4. Weber R, Sabin CA, Friis-Moller N, Reiss P, El-Sadr WM, et al. (2006) Liverrelated deaths in persons infected with the human immunodeficiency virus: the D:A:D study. Arch Intern Med 166: 1632-1641.

5. Lewden C, May T, Rosenthal E, Burty C, Bonnet F, et al. (2008) Changes in causes of death among adults infected by HIV between 2000 and 2005 The "Mortalite 2000 and 2005" surveys (ANRS EN19 and Mortavic). J Acquir Immune Defic Syndr 48: 590-598.

6. Thein HH, Yi Q, Dore GJ, Krahn MD (2008) Natural history of hepatitis C virus infection in HIV-infected individuals and the impact of HIV in the era of highly active antiretroviral therapy: a meta-analysis. AIDS 22: 1979-1991.

7. Pineda JA, Romero-Gomez M, Diaz-Garcia F, Giron-Gonzalez JA, Montero JL, et al. (2005) HIV coinfection shortens the survival of patients with hepatitis C virus-related decompensated cirrhosis. Hepatology 41: 779-789.

8. Wit FW, Weverling GJ, Weel J, Jurriaans S, Lange JM (2002) Incidence of and risk factors for severe hepatotoxicity associated with antiretroviral combination therapy. J Infect Dis 186: 23-31.

9. Nunez M (2006) Hepatotoxicity of antiretrovirals: incidence, mechanisms and management. J Hepatol 44: S132-S139.

10. Law WP, Dore GJ, Duncombe CJ, Mahanontharit A, Boyd MA, et al. (2003) Risk of severe hepatotoxicity associated with antiretroviral therapy in the HIV-NAT Cohort, Thailand, 1996-2001. AIDS 17: 2191-2199.

11. Soriano V, Puoti M, Sulkowski M, Mauss S, Cacoub P, et al. (2004) Care of patients with hepatitis $C$ and HIV co-infection. AIDS 18: 1-12.

12. Laurent C, Kouanfack C, Koulla-Shiro S, Nkoue N, Bourgeois A, et al. (2004) Effectiveness and safety of a generic fixed-dose combination of nevirapine, stavudine, and lamivudine in HIV-1-infected adults in Cameroon: open-label multicentre trial. Lancet 364: 29-34.

13. Ivers LC, Kendrick D, Doucette K (2005) Efficacy of antiretroviral therapy programs in resource-poor settings: a meta-analysis of the published literature. Clin Infect Dis 41: 217-224.

14. Madec Y, Laureillard D, Pinoges L, Fernandez M, Prak N, et al. (2007) Response to highly active antiretroviral therapy among severely immuno-compromised HIV-infected patients in Cambodia. AIDS 21: 351-359.

15. Janssens B, Raleigh B, Soeung S, Akao K, Te V, et al. (2007) Effectiveness of highly active antiretroviral therapy in HIV-positive children: evaluation at 12 months in a routine program in Cambodia. Pediatrics 120: e1134-1140.

16. Isaakidis P, Raguenaud ME, Te V, Tray CS, Akao K, et al. (2011) High survival and treatment success sustained after two and three years of first-line ART for children in Cambodia. J Int AIDS Soc 13: 11

17. Ferradini L, Laureillard D, Prak N, Ngeth C, Fernandez M, et al. (2007) Positive outcomes of HAART at 24 months in HIV-infected patients in Cambodia. AIDS 21: 2293-2301.

18. Segeral O, Limsreng S, Nouhin J, Hak C, Ngin S, et al. (2011) Short communication: Three Years Follow-Up of First-Line Antiretroviral Therapy in Cambodia: Negative Impact of Prior Antiretroviral Treatment. AIDS Res Hum Retroviruses 27: 597-603.
19. Thuring EG, Joller-Jemelka HI, Sareth H, Sokhan U, Reth C, et al. (1993) Prevalence of markers of hepatitis viruses A, B, C and of HIV in healthy individuals and patients of a Cambodian province. Southeast Asian J Trop Med Public Health 24: 239-249.

20. Sarmati L, Andreoni M, Suligoi B, Bugarini R, Uccella I, et al. (2003) Infection with human herpesvirus- 8 and its correlation with hepatitis $B$ virus and hepatitis $\mathrm{C}$ virus markers among rural populations in Cambodia. Am J Trop Med Hyg 68: 501-502.

21. Caruana SR, Kelly HA, De Silva SL, Chea L, Nuon S, et al. (2005) Knowledge about hepatitis and previous exposure to hepatitis viruses in immigrants and refugees from the Mekong Region. Aust N Z J Public Health 29: 64-68.

22. Luksamijarulkul P, Kaepan W, Klamphakorn S (2007) Hepatitis B virus seromarkers, hepatitis $C$ virus antibody and risk behaviors among middle age and older Thai males. Southeast Asian J Trop Med Public Health 38: 45-52.

23. Jutavijittum P, Yousukh A, Samountry B, Samountry K, Ounavong A, et al (2007) Seroprevalence of hepatitis B and C virus infections among Lao blood donors. Southeast Asian J Trop Med Public Health 38: 674-679.

24. Vong S, Perz JF, Sok S, Som S, Goldstein S, et al. (2005) Rapid assessment of injection practices in Cambodia, 2002. BMC Public Health 5: 56.

25. Dewost AV, Michaud P, Arfaoui S, Gache P, Lancrenon S (2006) Fast alcohol consumption evaluation: a screening instrument adapted for French general practitioners. Alcohol Clin Exp Res 30: 1889-1895.

26. Felsenstein $J(1996)$ Inferring phylogenies from protein sequences by parsimony, distance, and likelihood methods. Methods Enzymol 266: 418-427.

27. Budkowska A, Kakkanas A, Nerrienet E, Kalinina O, Maillard P, et al. (2011) Synonymous mutations in the core gene are linked to unusual serological profile in hepatitis $C$ virus infection. PLoS One 6: e15871.

28. Kesli R, Ozdemir M, Kurtoglu MG, Baykan M, Baysal B (2009) Evaluation and comparison of three different anti-hepatitis $C$ virus antibody tests based on chemiluminescence and enzyme-linked immunosorbent assay methods used in the diagnosis of hepatitis C infections in Turkey. J Int Med Res 37: 14201429.

29. Pham DA, Leuangwutiwong $P$, Jittmittraphap $A$, Luplertlop $N$, Bach $\mathrm{HK}$, et al. (2009) High prevalence of Hepatitis C virus genotype 6 in Vietnam. Asian Pac J Allergy Immunol 27: 153-160.

30. Verachai V, Phutiprawan T, Theamboonlers A, Chinchai T, Tanprasert S, et al. (2002) Prevalence and genotypes of hepatitis C virus infection among drug addicts and blood donors in Thailand. Southeast Asian J Trop Med Public Health 33: 849-851.

31. Carrat F, Bani-Sadr F, Pol S, Rosenthal E, Lunel-Fabiani F, et al. (2004) Pegylated interferon alfa-2b vs standard interferon alfa-2b, plus ribavirin, for chronic hepatitis $\mathrm{C}$ in HIV-infected patients: a randomized controlled trial. JAMA 292: 2839-2848.

32. Vergara S, Macias J, Rivero A, Gutierrez-Valencia A, Gonzalez-Serrano M et al. (2007) The use of transient elastometry for assessing liver fibrosis in patients with HIV and hepatitis C virus coinfection. Clin Infect Dis 45: 969-974.

33. Myers RP, Benhamou Y, Imbert-Bismut F, Thibault V, Bochet M, et al. (2003) Serum biochemical markers accurately predict liver fibrosis in HIV and hepatitis C virus co-infected patients. AIDS 17: 721-725

34. Moreno S, Garcia-Samaniego J, Moreno A, Ortega E, Pineda JA, et al. (2009) Noninvasive diagnosis of liver fibrosis in patients with HIV infection and HCVI HBV co-infection. J Viral Hepat 16: 249-258.

35. Nunes D, Fleming C, Offner G, O'Brien M, Tumilty S, et al. (2005) HIV infection does not affect the performance of noninvasive markers of fibrosis for the diagnosis of hepatitis C virus-related liver disease. J Acquir Immune Defic Syndr 40: 538-544.

36. Potter M, Odueyungbo A, Yang $H$, Saeed $S$, Klein MB, et al (2010) Impact of hepatitis $\mathrm{C}$ viral replication on CD4+ T-lymphocyte progression in HIV-HCV coinfection before and after antiretroviral therapy. AIDS 24: 1857-1865.

37. Braitstein P, Zala C, Yip B, Brinkhof MW, Moore D, et al. (2006) Immunologic response to antiretroviral therapy in hepatitis $C$ virus-coinfected adults in a population-based HIVIAIDS treatment program. J Infect Dis 193: 259-268.

38. Rockstroh JK, Mocroft A, Soriano V, Tural C, Losso MH, et al. (2005) Influence of hepatitis $\mathrm{C}$ virus infection on HIV-1 disease progression and response to highly active antiretroviral therapy. J Infect Dis 192: 992-1002. 
Citation: Lerolle N, Limsreng S, Fournier-Nicolle I, Ly S, Nouhin J, et al. (2012) High Frequency of Advanced Hepatic Disease among HIV/HCV CoInfected Patients in Cambodia: The HEPACAM Study (ANRS 12267). J AIDS Clinic Res 3:161. doi:10.4172/2155-6113.1000161

Page 7 of 7

39. Sulkowski MS, Thomas DL, Mehta SH, Chaisson RE, Moore RD (2002) Hepatotoxicity associated with nevirapine or efavirenz-containing antiretroviral therapy: role of hepatitis C and B infections. Hepatology 35: 182-189.

40. den Brinker M, Wit FW, Wertheim-van Dillen PM, Jurriaans S, Weel J, et al. (2000) Hepatitis B and C virus co-infection and the risk for hepatotoxicity of highly active antiretroviral therapy in HIV-1 infection. AIDS 14: 2895-2902.

41. Nunez M, Lana R, Mendoza JL, Martin-Carbonero L, Soriano V (2001) Risk factors for severe hepatic injury after introduction of highly active antiretroviral therapy. J Acquir Immune Defic Syndr 27: 426-431.

42. Mbougua JB, Laurent C, Kouanfack C, Bourgeois A, Ciaffi L, et al. (2010) Hepatotoxicity and effectiveness of a Nevirapine-based antiretroviral therapy in HIV-infected patients with or without viral hepatitis $\mathrm{B}$ or $\mathrm{C}$ infection in Cameroon. BMC Public Health 10: 105.

43. Qurishi N, Kreuzberg C, Luchters G, Effenberger W, Kupfer B, et al. (2003)
Effect of antiretroviral therapy on liver-related mortality in patients with HIV and hepatitis $C$ virus coinfection. Lancet 362: 1708-1713.

44. Labarga P, Soriano V, Vispo ME, Pinilla J, Martin-Carbonero L, et al. (2007) Hepatotoxicity of antiretroviral drugs is reduced after successful treatment of chronic hepatitis C in HIV-infected patients. J Infect Dis 196: 670-676.

45. Yu ML, Chuang WL (2009) Treatment of chronic hepatitis C in Asia: when Eas meets West. J Gastroenterol Hepatol 24: 336-345.

46. Tsang OT, Zee JS, Chan JM, Li RS, Kan YM, et al. (2010) Chronic hepatitis C genotype 6 responds better to pegylated interferon and ribavirin combination therapy than genotype 1. J Gastroenterol Hepatol 25: 766-771.

47. Ge D, Fellay J, Thompson AJ, Simon JS, Shianna KV, et al. (2009) Genetic variation in IL28B predicts hepatitis C treatment-induced viral clearance. Nature 461: 399-401. 